\title{
Correção de fenda palatina secundária traumática em cão - relato de caso
}

[Correction cleft palate secondary traumatic in dog - case report]

D.K.O. Bezerra ${ }^{1}$, C.F. João ${ }^{2}$, J.H. Sante ${ }^{3}$, L.F.M. Moreira ${ }^{4}$, A.E.C. Barbosa ${ }^{1}$, A.E.N. Carvalho ${ }^{1}$, F.A. Batista Júnior ${ }^{5}$

\author{
${ }^{1}$ Aluno de pós-graduação - Universidade Federal do Pará - Castanhal, PA \\ ${ }^{2}$ Universidade Federal do Pará - Castanhal, PA \\ ${ }^{3}$ Universidade de São Paulo - São Paulo, SP \\ ${ }^{4}$ Universidade Federal Rural da Amazônia - Belém, PA \\ ${ }^{5}$ Aluno de pós-graduação - Universidade do Estado do Pará - Belém, PA
}

\begin{abstract}
RESUMO
A fenda palatina é a comunicação entre a cavidade oral e a nasal através de um orifício no palato. Tem diversas etiologias, podendo ser congênita, traumática, por deficiência mineral ou por fatores hormonais. O diagnóstico é realizado por meio de exame físico da cavidade oral, e a correção cirúrgica é o tratamento de escolha. Em animais adultos, pode ser corrigida com o auxílio de retalho mucoperiosteal, apresentando bons resultados. Já em filhotes, a correção cirúrgica é mais complicada, com prognóstico menos favorável. Este trabalho relata o caso de um canino, fêmea, sem raça definida, adulta, com histórico de fenda palatina secundária, de origem traumática, no palato mole por ingestão de osso. Para a correção cirúrgica, primeiramente foi utilizada membrana biológica de pericárdio bovino, mas não se obteve êxito. O segundo procedimento foi realizado com retalho mucoperiosteal simples autólogo e, dois meses após o procedimento, já havia cicatrização completa. A técnica de retalho mucoperiosteal simples autólogo se mostrou eficaz no tratamento da fenda palatina, aliada aos cuidados adequados no pós-operatório.
\end{abstract}

Palavras-chave: palato, retalho mucoperiosteal, trauma

\begin{abstract}
The cleft palate is the communication between the oral and nasal cavity through an aperture in the palate, it's causes include an infinitude of factors: congenital, traumatic, mineral deficiency or hormonal. Examination of the oral cavity determines if the diagnosis and treatment is surgical. Correction in adult animals is performed with mucoperiosteal flap showing good results. However, surgical correction in puppies is more complicated with less favorable prognosis. This current work reports a case of an adult, female dog of undefined breed, with a history of secondary clef palate of traumatic origin in the soft palate due to bone ingestion. For correction, a biological membrane of bovine pericardium was used, but it was not successful, requiring a second surgical procedure performed with autologous simple mucoperiosteal flap. The last technique combined with adequate postoperative care was effective.
\end{abstract}

Keyword: palate, mucoperiosteal flap, trauma

\section{INTRODUÇÃO}

Fendas são defeitos estruturais no lábio, no palato ou em suas estruturas. São consideradas primárias quando ocorrem no lábio (leporino), ou secundárias, quando o defeito é no palato duro ou mole, com comunicação entre a cavidade oral e a nasal (Sante, 2014). Classificam-se como congênitas quando já existem ao nascimento, ou

Recebido em 10 de maio de 2017

Aceito em 23 de janeiro de 2019

E-mail: danikaisa.dk@gmail.com podem ser adquiridas. A fenda palatina adquirida pode ser causada por traumas na cabeça (atropelamentos, quedas), mordeduras (Silva et al., 2006), ferimentos por arma de fogo, queimaduras por fio elétrico (Galhardo et al., 2004) ou pode ser provocada por tumores orais (Contesini et al., 2003).

Após o diagnóstico, que é realizado por inspeção da cavidade oral, deve-se realizar a correção no menor tempo possível. Várias técnicas podem ser 
utilizadas para a reconstrução, como o uso de retalho mucoperiosteal autólogo, que permanece irrigado por uma das artérias palatinas para garantir a vascularização do tecido. Essa técnica exige que o animal tenha tecido viável no palato (Fossum, 2008). A técnica de retalho simples consiste em elevar do palato adjacente ao orifício um retalho mucoperiosteal dorsalmente ao defeito e perpendicular aos arcos dentários, devendo ser deslizado até a outra porção ventral da comunicação e suturado (Roza et al., 2012). Os resultados são satisfatórios quando são utilizadas técnicas cirúrgicas apropriadas para o tipo de defeito, mantendo a vascularização do local, além do uso de fios e cuidados adequados no pós-operatório (Bojrad, 2014).

Nos animais em que não há possibilidade de ser feita reconstrução com tecido autólogo (Salisbury, 2005; Roza et al., 2012; Fossum, 2008), várias técnicas que utilizam outros tipos de materiais são descritas para a correção do defeito, como o uso das membranas biológicas, como pericárdio bovino (Everton et al., 2010) ou enxerto utilizando pina auricular. Entre as membranas biológicas, o uso do pericárdio bovino se mostrou eficaz com a correção de fenda palatina traumática em um equino (Everton et al., 2010).

O prognóstico para a fenda palatina é desfavorável em casos de neonatos pela dificuldade de se fazer o manejo alimentar até o animal atingir o tamanho necessário para a realização da cirurgia. Animais que são alimentados por sonda até atingirem o tamanho necessário apresentam bom prognóstico (Dutra, 2008). O objetivo do presente trabalho é relatar um caso de fenda palatina secundária traumática, em região de palato mole em um cão, descrever as técnicas cirúrgicas empregadas, bem como a evolução do animal após correção cirúrgica.

\section{CASUÍSTICA}

Foi atendido no setor de clínica cirúrgica do Hospital Veterinário Mário Dias Teixeira, da Universidade Federal Rural da Amazônia, um canino, sem raça definida, fêmea inteira, de nove anos, que apresentava fenda em palato mole. $\mathrm{O}$ tutor relatou que o animal apresentava emagrecimento progressivo e tinha a lesão na cavidade oral com evolução de um mês, provavelmente ocasionada por um pedaço de osso ingerido. Relatou também que, após alimentação e ingestão de água, o animal apresentava espirros, saindo água e comida pelas narinas. Ao se examinar a cavidade oral, foi observada uma fenda em palato mole de aproximadamente $1 \mathrm{~cm}$ de diâmetro. Além disso, havia um pedaço de capim dentro da fenda (Fig. 1A). Os demais parâmetros clínicos do animal estavam dentro da normalidade. De acordo com o histórico e com os achados do exame físico, estabeleceu-se o diagnóstico de fenda palatina secundária, de origem traumática. Como tratamento, foi indicada a cirurgia reconstrutiva com a utilização de pericárdio bovino.

Três dias antes da cirurgia, o animal começou a ser medicado com metronidazol $(25 \mathrm{mg} / \mathrm{kg})$ associado a espiramicina $(75.000 \mathrm{UI} / \mathrm{kg})$ a cada 24 horas, e realizou-se limpeza da cavidade oral com solução de clorexidina $0,12 \%$, uma vez ao dia. O procedimento cirúrgico foi realizado utilizando-se pericárdio bovino conservado em glicerina a $98 \%$. As bordas da fenda foram desbridadas e, então, o pericárdio bovino foi suturado com fio de náilon $2 / 0$, com pontos isolados simples nas bordas da fenda (Fig. 1B).

O pós-operatório foi realizado na casa do proprietário, sendo prescrito cloridrato de tramadol $(4 \mathrm{mg} / \mathrm{kg})$ a cada 12 horas, por quatro dias, metronidazol $(30 \mathrm{mg} / \mathrm{kg})$, a cada 12 horas, por 10 dias, meloxicam $(0,1 \mathrm{mg} / \mathrm{kg})$ a cada 24 horas, por quatro dias, além da limpeza da cavidade oral por tempo indeterminado. Também foi indicada alimentação pastosa por 10 dias. O animal retornou ao Hospital 20 dias após a cirurgia, pois apresentou quadro de vômito e diarreia. $\mathrm{Na}$ inspeção da cavidade oral, foi observado que o implante de pericárdio bovino no palato mole havia se perdido, e a fenda aumentado de tamanho, medindo aproximadamente $1,5 \mathrm{~cm}$ de diâmetro (Fig. 2A).

Com o insucesso da primeira cirurgia, foi indicado novo procedimento, utilizando a técnica de retalho mucoperiosteal simples rotacional. A nova cirurgia foi realizada 49 dias após o primeiro procedimento cirúrgico. Inicialmente se delimitou a extensão do retalho a ser feito; a primeira incisão teve início na margem medial da fenda e seguiu rostralmente à direita da linha média do palato, atingindo um tamanho que pudesse fechar o defeito sem tensão nas suturas. Uma segunda incisão foi feita paralela à 
primeira, tangenciando a arcada dentária do lado direito, com o mesmo comprimento da primeira. Uma terceira incisão foi feita na porção rostral das duas primeiras, ligando-as. Assim estabelecida a configuração do retalho mucoperiosteal, este foi elevado com auxílio de elevador de periósteo, deixando exposto o osso palatino. A elevação foi feita até a base do retalho, de forma suave, para não comprometer a sua irrigação. Então, este foi cuidadosamente rotacionado para a esquerda e caudalmente, para se acomodar sobre a fenda, preenchendo-a totalmente. As bordas do retalho foram suturadas com pontos isolados simples, sendo usado o fio poliglecaprone 2/0 (Fig. 2B). Além disso, o animal recebeu uma sonda esofágica para fornecimento de alimento e medicamentos durante todo o pós-operatório, para evitar contato de alimento com a cavidade oral.

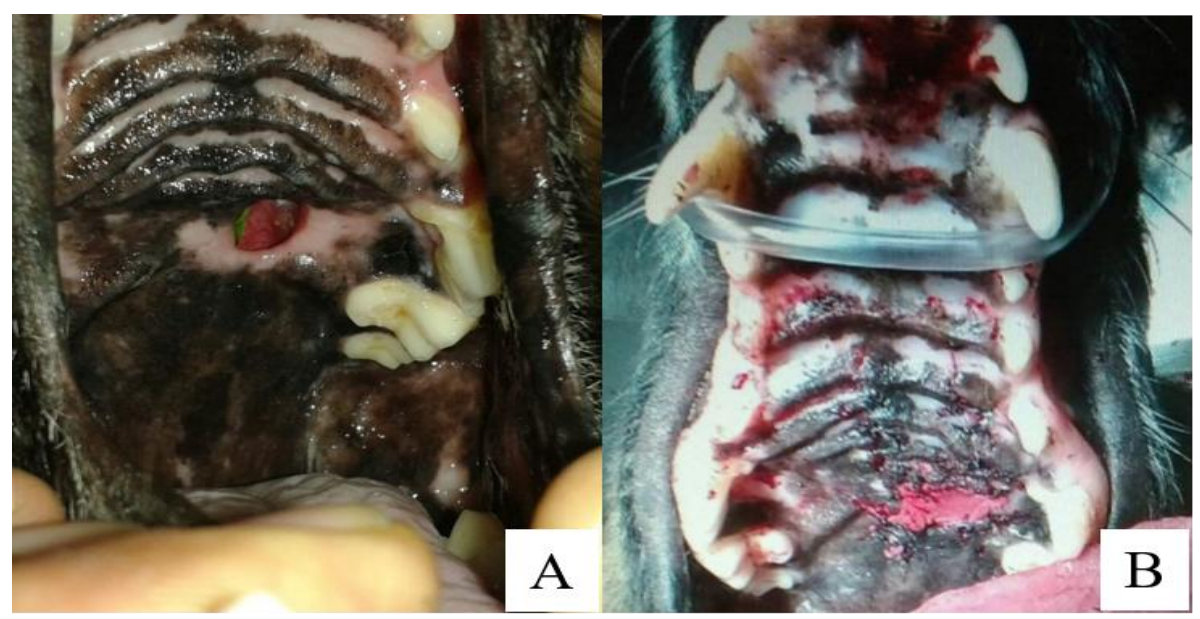

Figura 1. Canino, cavidade oral. A. Fenda palatina secundária traumática em região de palato mole, com a presença de corpo estranho semelhante a uma folha de capim. B. Fenda localizada em região de palato mole corrigida com pericárdio bovino.

Foi prescrito cloridrato de tramadol $(3 \mathrm{mg} / \mathrm{kg})$ a cada oito horas, por 10 dias, amoxicilina+clavulanato de potássio $(20 \mathrm{mg} / \mathrm{kg})$ a cada 12 horas, por 10 dias, dipirona $(25 \mathrm{mg} / \mathrm{kg})$ a cada oito horas, por cinco dias, cetoprofeno $(1 \mathrm{mg} / \mathrm{kg})$ a cada 24 horas, por quatro dias, e gluconato de clorexidina $0,12 \%$ sem álcool, para limpeza da cavidade oral, cinco vezes ao dia. Após seis horas da cirurgia, o animal apresentou o quadro de hematêmese e epistaxe intensa do lado direito. Foram acrescentadas outras medicações, como o ácido tranexâmico $(30 \mathrm{mg} / \mathrm{kg})$ endovenoso, a cada oito horas, durante três dias, e cloridrato de ranitidina $(2 \mathrm{mg} / \mathrm{kg})$ a cada oito horas, nas primeiras 48 horas, por via subcutânea e, após esse período, via sonda esofágica, durante sete dias. $\mathrm{O}$ citrato de maropitant foi aplicado em dose única $(0,1 \mathrm{ml} / \mathrm{kg})$, via subcutânea. Cessaram os vômitos e a epistaxe após quatro dias, mantendo-se apenas uma pequena quantidade de secreção nasal serossanguinolenta.
Quatro dias após a cirurgia, já havia discreta formação do tecido de granulação no osso palatino exposto pela retirada do retalho (Fig. $3 \mathrm{~A})$. Ao $11^{\mathrm{o}}$ dia de pós-operatório, a sonda esofágica foi arrancada pelo próprio animal, por descuido do proprietário, e, então, o animal passou a receber alimentação pastosa pela boca. Em 14 dias, o local de implantação do retalho já apresentava boa cicatrização, sem sinais de rejeição. Também havia a presença de tecido de granulação bem formado na região de onde foi retirado o retalho (Fig. 3B). Com 25 dias, não havia nenhum ponto de sutura do retalho e este já estava incorporado ao palato, o tecido de granulação já estava recobrindo praticamente todo o osso palatino inicialmente exposto (Fig. 3C). Com 38 dias, o tecido de granulação já recobria todo o osso palatino e a ferida cirúrgica do local da fenda estava totalmente cicatrizada (Fig. 3D). Depois de dois meses, a recuperação estava completa e o animal voltou a se alimentar de ração seca. 


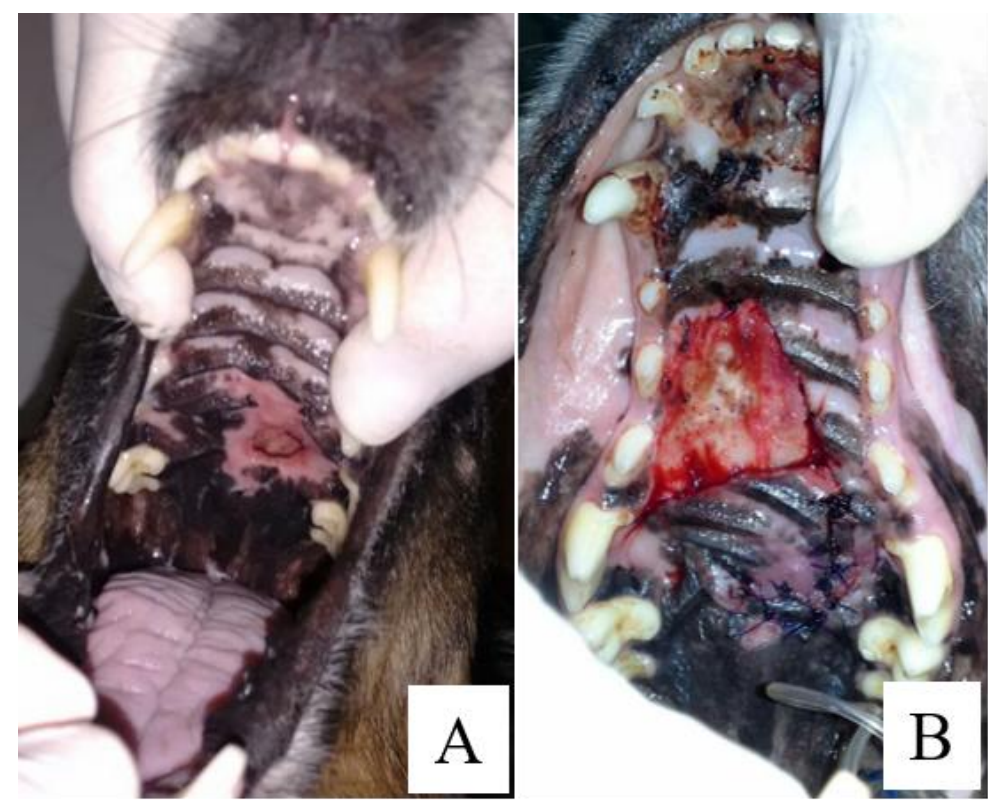

Figura 2. Canino, cavidade oral. A. Imagem fotográfica mostra a fenda palatina maior, após 20 dias da primeira correção cirúrgica e sem a presença do pericárdio bovino. B. Retalho mucoperiosteal simples.

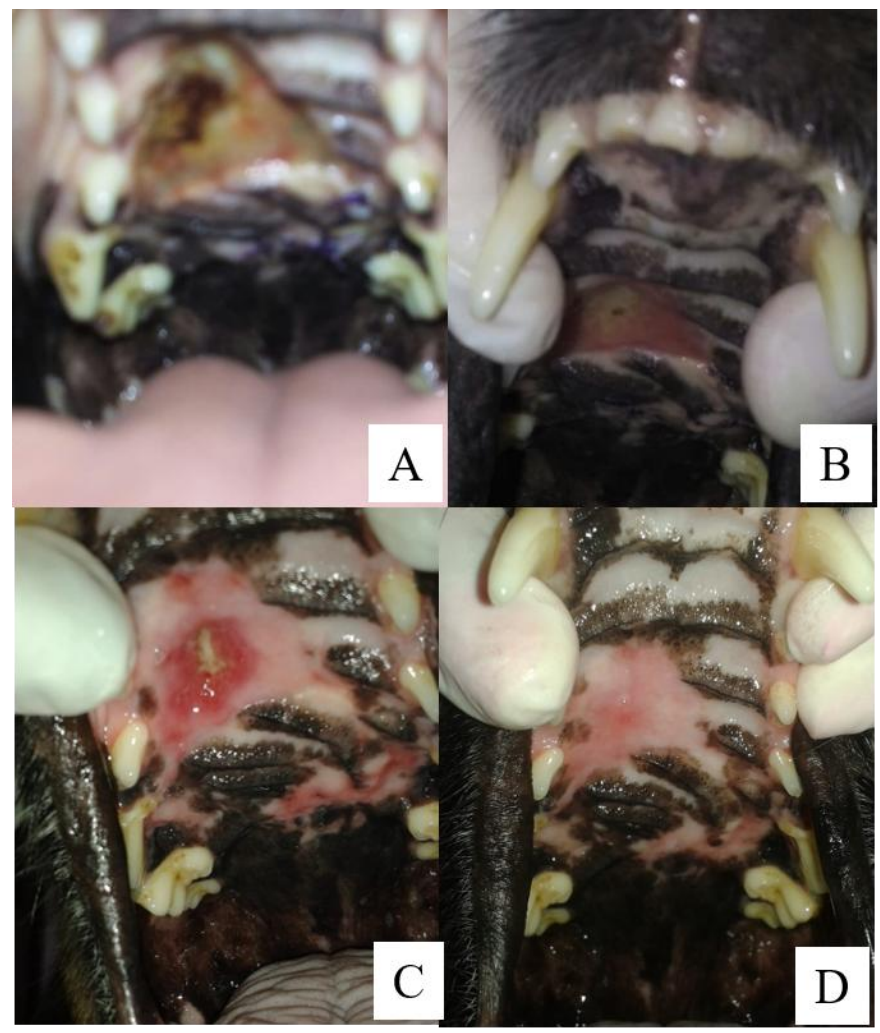

Figura 3. Canino, cavidade oral. A. Imagem fotográfica de quatro dias de pós-operatório, início da formação do tecido de granulação. B. 14 dias pós-cirúrgico, mostrando o tecido de granulação se formando. C. 25 dias pós-cirúrgico, mostrando o recobrimento do tecido de granulação em quase todo o osso palatino que ficou exposto e a ausência de pontos. D. 38 dias pós-cirúrgico, mostrando o tecido de granulação recobrindo todo o osso palatino e ferida cirúrgica cicatrizada. 


\section{DISCUSSÃO}

A fenda palatina em animais adultos é adquirida, e, no presente caso, foi ocasionada por lesão traumática por pedaço de osso ingerido pelo animal. A fenda foi classificada como secundária, já que apenas o palato estava afetado. A comunicação que se formou pela fenda palatina entre a cavidade oral e a nasal era responsável pela passagem de água e alimentos ingeridos pelo animal, para as narinas, o que provocava espirros, dor e incômodo para o animal e, consequentemente, emagrecimento progressivo. Apesar desses sintomas, o animal inicialmente não apresentava nenhum tipo de secreção nasal, não tinha alteração na auscultação pulmonar ou em exames complementares, que pudessem sugerir uma pneumonia por aspiração, que é comumente observada em animais com fenda palatina. Os principais sinais clínicos citados em animais com fenda palatina são descarga nasal mucopurulenta, tosse, espirros após ingestão de alimentos e água, anorexia, infecções do trato respiratório e pneumonia aspirativa (Galhardo et al., 2004).

O tratamento da afecção se baseia no fechamento da fenda, impedindo a comunicação entre a cavidade oral e a nasal. A primeira tentativa foi a utilização de pericárdio bovino. Membranas biológicas já foram utilizadas por outros autores, como Everton et al. (2010), que trataram a fenda palatina congênita em um potro com o centro tendíneo de diafragma bovino. $\mathrm{O}$ uso de membranas biológicas é viável devido à facilidade de obtenção e preparo, além do baixo custo. O pericárdio bovino é uma membrana biológica que tem bons resultados para corrigir diversos problemas. Ele tem como característica ser quase totalmente constituído de fibras de colágeno, assim tem baixa toxicidade e celularidade, além de poder ser recortado e organizado no tecido de acordo com o defeito (Oliveira et al., 2009). No caso em questão, houve deiscência dos pontos de sutura e perda do reparo. A falta de êxito no tratamento pode ser devido ao pós-operatório realizado, que não foi o ideal para esse tipo de cirurgia, já que, após o procedimento, o animal continuou se alimentando normalmente com alimentação pastosa. $\mathrm{O}$ atrito do alimento com o local da cirurgia, além do seu acúmulo no local de sutura, e a contaminação do local, podem ter provocado a deiscência dos pontos, afetando a eficácia da técnica utilizada. Essa condição está de acordo com o trabalho de Dutra (2008), que afirma que a recidiva se dá pela própria condição das cavidades oral e nasal (repletas de bactérias, restos alimentares e saliva), além da movimentação da língua sobre os pontos.

No segundo procedimento cirúrgico, optou-se pela técnica do retalho simples rotacional. Essa técnica também foi relatada por Roza et al. (2012), que descrevem o uso de retalho simples elevando um retalho mucoperiosteal dorsalmente ao defeito e perpendicularmente aos arcos dentários, devendo ser deslizado até a outra porção ventral da comunicação e suturado. Quando se realiza um "flap" de mucoperiósteo, este deverá vir incorporado a uma artéria palatina para que haja suprimento sanguíneo naquele local, evitando-se a necrose (Salisbury, 2005).

Durante a segunda cirurgia, foi colocada uma sonda esofágica no animal para alimentação pastosa no pós-cirúrgico, que permaneceu por 11 dias. Durante esse período, foi possível alimentar o animal sem que a comida entrasse em contato com a ferida cirúrgica, garantindo maior limpeza e menor atrito do local, o que contribuiu para não deiscência de sutura. Segundo Fossum (2008), a alimentação deve ser pastosa durante sete a 14 dias após a cirurgia e deve ser realizada por sonda de esofagostomia ou gastrostomia, o que ajuda na cicatrização da ferida cirúrgica.

O processo de cicatrização foi adequado, sendo observado, em quatro dias de pós-operatório, o início da formação do tecido de granulação. Williams e Moores (2013) afirmam que o tecido de granulação começa a se formar entre três e cinco dias após a lesão do tecido, formando uma barreira protetora e fornecendo uma superfície para ocorrer a epitelização. Com 15 dias, já havia maior quantidade de tecido de granulação recobrindo quase todo o defeito e, com 38 dias após a cirurgia, o tecido já recobria todo o defeito. 
Várias complicações podem ocorrer no pósoperatório, entre elas deiscência dos pontos, cicatrização incompleta e recidiva com concomitante processo inflamatório e infeccioso (Nogueira, 2009), o que foi observado após a primeira cirurgia. Esse quadro não ocorreu após a segunda cirurgia, mostrando que a técnica empregada, o material utilizado, o manuseio e os cuidados no pós-operatório foram adequados.

\section{CONCLUSÃO}

A técnica do retalho mucoperiosteal associada a alimentação por meio de sonda esofágica e limpeza da ferida cirúrgica foi eficaz no tratamento de fenda palatina secundária traumática.

\section{REFERÊNCIAS}

BOJRAD, M.J. Defeito palatal. In:. Mecanismos das doenças em cirurgias de pequenos animais. 3.ed. São Paulo: Roca, 2014. p . 174-178.

CONTENSINI, E.A.; PIPPI, N.L.; BECK, C.A.C. et al. Aspectos clínicos e macroscópicos da palatoplastia imediata com implante de cartilagem da pina articular, conservada em glicerina a $98 \%$, após indução experimental de fenda palatina em cães. Cienc. Rural, v.33, p.103-108, 2003.

DUTRA, A.T. Defeitos palatinos congênitos. 2008. 23f. Trabalho de Conclusão de Curso (Especialização em Clínica Médica e Cirúrgica de Pequenos Animais) - Universidade Castelo Branco, São José do Rio Preto, SP.

EVERTON, E.B.; OLIVEIRA, L.C.R.; CARVALHO, L.T.R. et al. Correção cirúrgica de fenda palatina secundária em um equino com uso de membrana biológica. In: CONGRESSO BRASILEIRO DE CIRURGIA E ANESTESIOLOGIA VETERINÁRIA, 9, 2010, Rio de Janeiro. Anais... Rio de Janeiro: [s.n], 2010. p.130-133. (Resumo).

FOSSUM, T.W. Cirurgia do sistema digestório. In: Cirurgia de pequenos animais. 3.ed. Rio de Janeiro: $\quad$ Elsevier, $2008 . \quad$ p.350-361.
GALHARDO, A.; COLETA, F.E.D.; SANTANA, A.E. et al. Reparo da luz da narina direita e oclusão de fístula oronasal decorrente de miíase em um cão (Canis familiaris). Cirurgia de pequenos animais. Braz. J. Vet. Res. Anim. Sci., v.4, p.127, 2004.

NOGUEIRA, R.M. Fístula oronasal em cão. Reparo com flape simples associado a fator proteico angiogênico purificado do látex de seringueira, veiculado com matriz de esponja de colágeno. Estudo experimental. 2009. 46f. Dissertação (Mestrado em Cirurgia Veterinária) - Faculdade de Ciências Agrárias e Veterinárias - UNESP, Campus de Jaboticabal, São Paulo, SP.

OLIVEIRA, L.L.; SOUZA, D.B.; ABÍLIO, E.W.J.; CARVALHO, E.C. Métodos de preservação de membranas biológicas para uso cirúrgico. J. Bras. Cienc. Anim., v.3, p.175-188, 2009.

ROZA, M.R.; CORRÊA, H.L.; GIOSO, M.A. Odontologia e cirurgia bucomaxilofacial (cirurgia dentária e da cavidade oral). In. OLIVEIRA, A.L.A. Técnicas cirúrgicas de pequenos animais. Rio de Janeiro: Elsevier, 2012. p.400-415.

SALISBURY, S.K. Cavidade oral. In: BOJRAB, M.J. Técnicas atuais em cirurgia de pequenos animais. 3.ed. São Paulo: Roca, 2005. p. 144152.

SANTE, J.H. Correção de fenda palatina secundária causada por tumor venéreo transmissível. 2014. 41f. Dissertação (Curso de Pós-graduação Lato Sensu em Odontologia Veterinária) - Faculdade de Medicina Veterinária e Zootecnia, Universidade de São Paulo, São Paulo, SP.

SILVA, M.R.; ALEIXO, G.A.; SÁ, F.B.; COELHO, M.C.O.C. Redução de fenda palatina secundária em um gato- relato de caso. Cienc. Vet. Trop., v.9, p.97-101, 2006.

WILliAMS, J.; MOORES, A. Biologia da cicatrização de feridas. In: WILLIAMS, J.; MOORES, A. Manual de feridas em cães $e$ gatos. São Paulo: Roca, 2013. p.1-14. 